\title{
Divergência genética entre acessos de mamoeiro por meio de variáveis morfoagronômicas
}

\section{Genetic divergence among papaya accessions by morphoagronomic traits}

\author{
Silvana Silva Red Quintal ${ }^{1}$; Alexandre Pio Viana ${ }^{2 *}$; Leandro Simões Azeredo \\ Gonçalves $^{3}$; Messias Gonzaga Pereira²; Antônio Teixeira do Amaral Júnior ${ }^{2}$
}

\section{Resumo}

O presente trabalho teve como objetivo quantificar a variabilidade genética entre 46 acessos de mamoeiro dos grupos Solo e Formosa utilizando 19 variáveis morfoagronômicas separadamente e em conjunto, e verificar a eficiência da análise conjunta no estudo da diversidade genética. O experimento foi conduzido em três épocas distintas (maio e agosto de 2007, e novembro de 2008), no município de Linhares-ES, utilizando-se delineamento em blocos casualizados, com duas repetições e 20 plantas por parcela em fileira dupla. As características quantitativas foram submetidas à análise de variância e posteriormente, utilizadas para estimar a distância de Mahalanobis, enquanto para os descritores qualitativos utilizouse o coeficiente de coincidência simples. A análise conjunta das variáveis quantitativas e qualitativas foi estimada com base no algoritmo de Gower. As matrizes de distâncias foram comparadas usando a correlação de Mantel com 1000 permutações. Posteriormente, foi realizado o agrupamento dos acessos pelo método UPGMA. Embora tenha sido constituído número igual de grupos (sete), os dois tipos de variáveis separadamente ou em conjunto não possibilitaram a formação de agrupamentos consideravelmente semelhantes para o grupo Formosa. Ao contrário, os acessos do grupo heterótico Solo ficaram alocados praticamente no grupo I em relação a todos os métodos de distância. O agrupamento formado pelos dados em conjunto proporcionou maior disjunção dos genótipos, decorrente de maior homogeneidade dentro dos grupos e heterogeneidade entre os grupos.

Palavras-chave: Carica papaya L., análise combinada, banco de germoplasma, algoritmo de Gower

\begin{abstract}
This study aimed to quantify genetic variability among 46 accessions of papaya from 'Solo' and 'Formosa' groups using 19 morphoagronomic traits separately and simultaneously, and to evaluate the efficiency of simultaneous analysis. The experiment was conducted for three growing seasons (May and August 2007, and November 2008), in Linhares-ES, using a randomized block design with two replications and 20 plants in two rows per plot. Quantitative traits were analyzed by analysis of variance and then used to estimate the Mahalanobis distance, while for the qualitative traits it was used the coefficient of simple coincidence. The genetic distance for the joint analysis was estimated based on the algorithm of Gower. The matrices of distance were compared using the Mantel correlation with 1000 permutations. The clusters of accessions were performed by UPGMA. Although they have made the same number of groups (seven), both types of variables separately and jointly did not allow the
\end{abstract}

1 Eng ${ }^{\circ}$ Agr $^{\circ}$, Doutorando em Produção Vegetal, Universidade Estadual do Norte Fluminense Darcy Ribeiro, UENF, Campos dos Goytacazes, RJ. E-mail: silvanared@hotmail.com

2 Engenheiros Agrônomos, Prof. Dr. da UENF, Campos dos Goytacazes, RJ. E-mail: pirapora@uenf.br; messias@uenf.br; amaraljr@uenf.br

3 Eng ${ }^{\circ}$ Agr $^{\circ}$, Dr. da UENF, Campos dos Goytacazes, RJ. E-mail: 1sagrural@yahoo.com.br

* Autor para correspondência 
formation of groups substantially similar to the group 'Formosa'. On the other hand, the accessions of 'Solo' group were allocated practically in the group I for all distance used. The cluster formed by the data simultaneously provided greater disjunction of accessions, due to greater homogeneity within groups and heterogeneity among groups.

Key words: Carica papaya L., combined analysis, germoplasm bank, Gower algorithm

\section{Introdução}

O mamoeiro (Carica papaya L.), importante fruteira, seja no aspecto de mercado ou em relação ao valor nutracêutico; atualmente, tem atraído melhoristas para a geração de formas com adaptação a diferentes condições edafoclimáticas (EUSTICE et al., 2008; CAVALCANTE et al., 2010). Em 2007, o Brasil foi o maior produtor mundial, com média estimada de 1,8 milhões de toneladas, o que correspondeu a $25,13 \%$ da produção mundial (FAO, 2009).

A despeito da elevada produção e consumo de mamão no Brasil, a cultura possui várias limitações para expansão da área de cultivo e, mesmo, para a manutenção de plantios; decorrente, sobretudo, das elevadas incidências de pragas e doenças (MARIN et al., 2006a; MORAIS et al., 2007; SUZUKI; ZAMBOLIM; LIBERATO, 2007; MARTELLETO et al., 2008; RAMOS et al., 2008). Para minimizar esse cenário, opção exequível é a obtenção de híbridos provenientes de diferentes grupos heteróticos (MARIN et al., 2006a; MARIN et al., 2006b; IDE et al., 2009). Apesar da propalada reduzida distância genética entre dois grupos de mamoeiro (DANTAS; LIMA, 2001), efeitos de heterobeltiose são comuns entre híbridos dos grupos Solo e Formosa (MARIN et al., 2006a; MARIN et al., 2006b; IDE et al., 2009).

Nesse contexto, os bancos de germoplasma assumem importância fundamental, particularmente no que se refere à variabilidade genética necessária para subsidiar o melhoramento de plantas na obtenção de genótipos superiores com distintas constituições gênicas. As espécies silvestres, as variedades locais e as cultivares obsoletas podem fornecer genes que conferem maior adaptação a estresses ambientais, bem como resistência a inúmeras pragas e doenças (GEPTS, 2006; GONÇALVES et al., 2008). Entretanto, esses acessos mantidos em bancos de germoplasma devem ser caracterizados e avaliados com o objetivo de conhecer os materiais genéticos antes de introduzilos em programa de melhoramento, evitando o uso de genomas reduntantes, comumente denonimados duplicatas (FRANCO et al., 2005; GEPTS, 2006; SUDRÉ et al., 2010).

$\mathrm{Na}$ caracterização e avaliação dos acessos, informações sobre variáveis quantitativas e qualitativas proporcionam maior acurácia na identificação de genomas contrastantes (MOHAMMADI; PRASANNA, 2003; CROSSA; FRANCO, 2004; GONÇALVES et al., 2008; GONÇALVES et al., 2009; SUDRÉ et al., 2010). Logicamente que tal situação decorre de uma maior capitalização da expressão gênica em uma única matriz de dados reunindo os diferentes tipos de variáveis (GONÇALVES et al., 2009). Em relação aos agrupamentos realizados separadamente para cada tipo de variável, não é incomum a identificação de incongruências (GONÇALVES et al., 2008; TSIVELIKAS et al., 2009).

Dentre as opções de análise simultâneas de diferentes tipos de variáveis, o algoritmo de Gower (1971) é um procedimento de pouca complexidade e que tem produzido resultados confiáveis, embora ainda pouco explorados pelos pesquisadores que atuam na área de recursos genéticos vegetais para detecção da variabilidade em bancos de germoplasmas. Trabalhos recentes vêm descrevendo o uso dessa metodologia, como Rodríguez et al. (2005) em investigação com Brassica napus L.; Vieira et al. (2007) e Bertan et al. (2009) em estudo com, Triticum aestivum L.; Gonçalves et al. (2008) e Rocha et al. (2010) na avaliação de Solanum 
lycopersicum; Tsivelikas et al. (2009), em trabalho com Curcubita spp; e Moura et al. (2010) com Capsicum chinense.

Por conseguinte, julgou-se oportuno o desenvolvimento do presente estudo que teve os intentos de: (i) quantificar a variabilidade presente em 46 genótipos de mamoeiro utilizando variáveis morfoagronômicas quantitativas e qualitativas separadamente, e em conjunto; e (ii) verificar a eficiência da análise conjunta no estudo da diversidade.

\section{Material e Métodos}

Foram avaliados 46 acessos de mamoeiro da coleção de germoplasma da Universidade Estadual do Norte Fluminense Darcy Ribeiro (UENF) e da Empresa Caliman (Tabela 1). Os experimentos foram conduzidos em campo, no município de Linhares, ES, em três épocas distintas. As épocas avaliadas foram: maio e agosto de 2007; e novembro de 2008. Utilizou-se o delineamento em blocos casualizados, com duas repetições e com 20 plantas por parcela em fileira dupla, com espaçamento de $3,6 \times 2,0 \times 1,5 \mathrm{~m}$.

Tabela 1. Acessos de mamoeiro do grupo Solo e Formosa.

\begin{tabular}{|c|c|c|c|}
\hline \multicolumn{4}{|c|}{ Carica papaya $\mathrm{L}$. } \\
\hline \multicolumn{2}{|c|}{ Grupo Formosa } & \multicolumn{2}{|c|}{ Grupo Solo } \\
\hline Denominação do acesso & Procedência & Denominação do acesso & Procedência \\
\hline Costa Rica & UENF & Caliman M5 & Caliman Agrícola \\
\hline Triwan Et & Caliman Agrícola & SS 783 & UENF \\
\hline Tailândia & EBDA-BA & Diva & Caliman Agrícola \\
\hline Mamão Bené & Caliman Agrícola & Grampola & Caliman Agrícola \\
\hline Maradol (orig. México) & Cuba & Sunrise Solo & Caliman Agrícola \\
\hline Maradol (grande limão) & Cuba & Caliman AM & Caliman Agrícola \\
\hline Sekati & Caliman Agrícola & Caliman GB & Caliman Agrícola \\
\hline STZ-52 & Caliman Agrícola & Caliman SG & Caliman Agrícola \\
\hline UENF/CALIMAN 01 & Caliman Agrícola & Caliman G & Caliman Agrícola \\
\hline Golden TF & Caliman Agrícola & Sunrise Solo $72 / 12$ & Papaya Ceres \\
\hline STA H III - 11A 8X & Caliman Agrícola & Kapoho Solo PAM & CNPMFT Cruz das Almas \\
\hline STA H III - 50 09X & Caliman Agrícola & BSA & Papaya Ceres \\
\hline STA H III - 02 01X & Caliman Agrícola & SS TJ & Papaya Ceres \\
\hline STA H III - 04 02X & Caliman Agrícola & São Mateus & Papaya Ceres \\
\hline Papaya 42 F & Caliman Agrícola & Kapoho Solo PV & - \\
\hline Papaya 45 FR & Caliman Agrícola & Sunrise Solo PT & Caliman Agrícola \\
\hline Papaya 46 C & Caliman Agrícola & Waimanalo & CNPMFT Cruz das Almas \\
\hline Caliman FMV & Caliman Agrícola & Mamão Roxo & - \\
\hline Tainung & Caliman Agrícola & BSA-Super & UENF \\
\hline STZ 23 PL & Caliman Agrícola & Grand golden & Caliman Agrícola \\
\hline 39 PLT - 03 BLII & Caliman Agrícola & THB STZ 39 & Caliman Agrícola \\
\hline Caliman B5 & Caliman Agrícola & & \\
\hline Formosa G & Caliman Agrícola & & \\
\hline Formosa B & Caliman Agrícola & & \\
\hline JS-12-4 & UENF/Caliman Agrícola & & \\
\hline
\end{tabular}

Fonte: Elaboração dos autores.

Na caracterização morfoagronômica dos acessos foram utilizados 19 descritores, estabelecidos pelo International Board for Plant Genetic Resources, atualmente Bioversity International (IBPGR, 1988), com algumas alterações sugeridas por Pinto (1999), sendo oito quantitativas e 11 qualitativas (Tabela 2). 
Tabela 2. Descritores usados para caracterização e avaliação de 46 acessos de mamoeiro do banco de germoplasma da UENF/CALIMAN.

Descritores

Descritores Qualitativos

- Tipo de hermafroditismo na planta

Escala 1-5 (1= muitas flores estéreis e poucas flores hermafroditas perfeitas, ausência de carpeloidia e pentandria; $2=$ poucas flores estéreis e muitas flores hermafroditas perfeitas, ausência de carpeloidia e pentandria; $3=$ poucas flores estéreis, muitas flores hermafroditas perfeitas e poucas carpelóides e pentândricas; $4=$ muitas flores hermafroditas perfeitas e poucas carpelóides e pentândricas; $5=$ poucas flores hermafroditas perfeitas e muitas carpelóides e pentândricas).

- Tipo de florescimento

Escala 1-2 (1=inflorescência; $2=$ Ambas - flores isoladas e inflorescência)

- Densidade de inflorescência no caule

Escala 1-3 (1= densa; $2=$ média; $3=$ esparsa $)$

- Densidade de flores na inflorescência

Escala 1-3 (1= densa; $2=$ média; $3=$ esparsa $)$

- Coloração do pedúnculo da inflorescência

- Coloração dos lóbulos da corola

- Uniformidade de distribuição dos frutos

- Coloração da casca do fruto imaturo

- Formato de frutos

- Formato da base do fruto

Escala 1-2 (1= esverdeado; $2=$ púrpura $)$

Escala 1-3 (1= creme; $2=$ amarelo; $3=$ amarelo/verde com manchas arroxeadas)

Escala 1-2 (1= uniforme; $2=$ desuniforme $)$

Escala 1-2 (1= verde $b ; 2=$ verde $c)$

Escala $1-7(1=$ elongata; $2=$ pêra; $3=$ clava; $4=$ ameixa; $5=$ alongadoafiliado; $6=$ alongado pêra; $7=$ oblongo pêra)

leve depressão

- Formato da cavidade central do fruto

Escala 1-5 (1= irregular; $2=$ arredondada; $3=$ angular; $4=$ formato aproximado de estrela; $5=$ estrela)

\section{Descritores Quantitativos}

- Peso do fruto

- Comprimento do fruto

- Diâmetro do fruto

- Firmeza interna do fruto

- Firmeza externa do fruto

- Espessura da polpa

- Sólidos solúveis totais

- Incidência de mancha fisiológico
Obtido em balança eletrônica (g).

Medido a partir do comprimento longitudinal dos frutos, com a utilização de paquímetro $(\mathrm{cm})$.

Medido a partir do comprimento transversal dos frutos, com a utilização de paquímetro $(\mathrm{cm})$.

Determinada em quatro pontos equidistante de cada face do fruto, com utilização do penetrômetro $(\mathrm{N})$.

Determinada em quatro pontos equidistante de cada face do fruto, com utilização do penetrômetro $(\mathrm{N})$.

Medido pelo comprimento lateral da polpa dos frutos, com a utilização de paquímetro $(\mathrm{cm})$.

Medido por meio do suco extraído da polpa do fruto. As leituras foram efetuadas em um refratômetro ( ${ }^{\circ}$ Brix).

Determinadas por meio de um sistema de notas variando de 1 a 6 , de acordo com o grau de incidência.

Fonte: Elaboração dos autores. 
Para as variáveis quantitativas foram realizadas as análises de variância (Tabela 3) e posteriormente foi calculada a distância generalizada de Mahalanobis, enquanto para as variáveis qualitativas utilizou-se o índice de coincidência simples. A distância genética para a análise conjunta das variáveis quantitativas e qualitativas foi realizada com base no algoritmo de Gower (1971).
As matrizes de distância foram comparadas usando a correlação de Mantel com 1000 permutações. Posteriormente, foi realizado o agrupamento dos acessos pelo método Unweighted Pair-Group Method Using an Arithmetic Average (UPGMA). A validação dos agrupamentos foi determinada pelo coeficiente de correlação cofenético (CCC). A análise estatística foi realizada por meio do uso do programa R (http://www.rproject.org).

Tabela 3. Análise de variância conjunta de oito características agronômicas avaliadas em 46 acessos de mamoeiro do Banco de Germoplasma da UENF/CALIMAN.

\begin{tabular}{|c|c|c|c|c|c|c|c|c|c|}
\hline \multirow{2}{*}{$\mathrm{FV}$} & \multirow{2}{*}{ GL } & \multicolumn{8}{|c|}{ Quadrados Médios ${ }^{1 /}$} \\
\hline & & $\mathrm{PF}$ & $\mathrm{CF}$ & $\mathrm{DF}$ & EP & TSS & FE & FI & Mancha \\
\hline Bloco & 1 & 137498,32 & 5,11 & 4,94 & 0,40 & 0,0002 & 298,48 & 61,25 & 0,25 \\
\hline $\begin{array}{c}\text { Genótipo } \\
\text { (G) }\end{array}$ & 45 & $1157835,00^{* *}$ & $182,83^{* *}$ & $18,20^{* *}$ & $0,94^{* *}$ & $7,69^{* *}$ & $15314,46^{* *}$ & $9549,09^{* * *}$ & $0,11^{* *}$ \\
\hline $\begin{array}{l}\text { Época } \\
\text { (E) }\end{array}$ & 2 & $1990655,05^{* *}$ & $3,86^{* *}$ & $7,67^{* *}$ & $3,55^{* *}$ & $0,28^{* *}$ & $23494,05^{* *}$ & $9971,71^{* * *}$ & $1,76^{* *}$ \\
\hline $\mathrm{G} \times \mathrm{E}$ & 90 & $208666,20^{* *}$ & $5,94^{* *}$ & $3,71^{* *}$ & $0,11^{* *}$ & $1,30^{* *}$ & $552,32^{* *}$ & $321,12^{* *}$ & $0,04^{* *}$ \\
\hline Resíduo & 137 & 32256,12 & 3,74 & 0,82 & 0,04 & 0,79 & 398,30 & 242,86 & 0,02 \\
\hline Média & & 701,70 & 17,20 & 9,27 & 2,48 & 10,55 & 131,32 & 98,80 & 1,46 \\
\hline $\mathrm{CVe}$ & & 25,59 & 11,24 & 9,79 & 7,81 & 8,45 & 15,20 & 15,77 & 9,57 \\
\hline
\end{tabular}

${ }^{* *}=$ significativo a $1 \%$ de probabilidade. ${ }^{1 /} \mathrm{PF}=$ peso do fruto $(\mathrm{g}) ; \mathrm{CF}=$ comprimento do fruto $(\mathrm{cm}) ; \mathrm{DF}=$ diâmetro do fruto $(\mathrm{cm}) ;$ $\mathrm{EP}=$ espessura da polpa $(\mathrm{cm}) ; \mathrm{TSS}=$ teor de sólidos solúveis totais $\left({ }^{\circ} \mathrm{BRIX}\right) ; \mathrm{FE}=$ firmeza externa dos frutos $(\mathrm{N}) ; \mathrm{FI}=$ firmeza interna dos frutos $(\mathrm{N})$; e Mancha = mancha fisiológica (notas).

\section{Resultado e Discussão}

Houve diferenças significativas em nível de $1 \%$ de probabilidade pelo teste $\mathrm{F}$ para todas as características quantitativas avaliadas em relação às fontes de variação Genótipos, Época e Genótipos versus Época (Tabela 3). A variação dos tratamentos indica a possibilidade de ocorrência de variabilidade entre os acessos avaliados, o que era presumível, em virtude da coleção ser composta por germoplasma de distintos grupos heteróticos. A ocorrência de significância para a fonte de variação Época demonstra que as condições edafoclimáticas foram distintas, favorecendo a expressão das diferenciações genéticas entre os materiais avaliados. Em relação à interação Genótipos versus Épocas, pode-se inferir sobre a existência de comportamento diferenciado entre os acessos quando submetidos a mudanças ambientais. Segundo Cruz, Regazzi e Carneiro (2004) este comportamento diferenciado é causado por fatores fisiológicos e bioquímicos próprios de cada acesso.

É consabido que a interação genótipos versus ambientes torna-se um complicador a mais para o estudo da diversidade genética quando se dispõem de variáveis quantitativas (GONÇALVES et al., 2008). Entretanto, Miranda et al. (2003) objetivando avaliar o potencial de melhoramento e a divergência genética de nove cultivares de milho pipoca, selecionaram o ambiente que proporcionou a menor interação das cultivares com determinada condição edafoclimática. Relativizando a prerrogativa de Miranda et al. (2003) para o presente trabalho, tem- 
se que o período de novembro de 2008 foi o que resultou em menores interações entre os genótipos com o ambiente para a maioria das características estudadas, ou seja, apresentando os menores valores para o quadrado médio residual. Por conseguinte, definiu-se como o mais indicado para o estudo de diversidade.

Pela análise de agrupamento das variáveis quantitativas, houve a formação de sete grupos, com base na média das distâncias da matriz de agrupamento (Figura 1). Os acessos do grupo Solo ficaram alocados apenas no grupo I, enquanto os representantes do tipo Formosa estiveram presentes em todos os grupos. Observaram-se menores valores para as características peso (variando de 222,50 a 566,67 g), comprimento (variando de 11,50 a 14,62 $\mathrm{cm})$, firmeza externa $(95,04$ a 131,29 N), e firmeza interna (71,32 a 85,82 N) dos frutos; e altos teores de sólido solúveis totais (10,07 a 12,30 Brix) para o grupo I; enquanto o grupo VI, formado pelos acessos Maradol (originário do México) e Maradol (designado 'grande limão') revelou os maiores pesos (2643,33 e $24475 \mathrm{~g}$, respectivamente) e comprimentos $(29,65$ e 29,55 cm, respectivamente) dos frutos. Esse grupo também se destacou quanto às características espessura da polpa $(3,49$ a $3,45 \mathrm{~cm}$, respectivamente) e produtividade $(49,51 \mathrm{e}$ $60,78 \mathrm{Kg}$.parcela ${ }^{-1}$, respectivamente). O grupo III, representado pelo acesso Caliman FMV, destacouse dos demais em relação à firmeza externa $(215 \mathrm{~N})$ e interna $(174,02 \mathrm{~N})$ do fruto; ao passo que o grupo $\mathrm{V}$, representado pelo acesso Tailândia, teve ênfase pelas estimativas das características diâmetro do fruto $(14,38 \mathrm{~cm})$, espessura da polpa $(3,48 \mathrm{~cm})$ e produtividade $\left(50,38 \mathrm{Kg} \cdot\right.$ parcela $\left.^{-1}\right)$.

No que tange às variáveis qualitativas, os acessos Grampola e Grand Golden; e SS TJ e STZ-52 não se diferenciaram pelos descritores morfológicos estudados. Pela análise de agrupamento por UPGMA, houve a formação também de sete grupos, considerando a média das distâncias da matriz de agrupamento (Figura 2). O grupo I foi o que congregou o maior número de genótipos, totalizando 32 acessos (69,56\%). Com exceção de Caliman SG e de Mamão roxo, os demais acessos representativos de Solo se concentraram neste grupo. Ainda em relação ao grupo I, constatou-se haver predomínio de acessos com poucas flores estéreis e muitas flores hermafroditas perfeitas, bem como ausência de carpeloidia e petandria; além de frutos com formato de pêra.

O grupo II, ao reunir os acessos Calimosa e Tailândia, revelou-se mais homogêneo em relação ao demais, para a maioria das características; entretanto, Tailândia formou poucas flores hermafroditas perfeitas e conteve muitas flores carpelóides e petândricas - características indesejáveis em plantios comerciais, por originar frutos deformados, que são pouco apreciados para consumo in natura. Os grupos III e IV foram formados por três acessos cada, destacando-se o genótipo Maradol, de origem Mexicana, por ser o único acesso da coleção que apresentou coloração amarela nos lóbulos da corola. O grupo V, em sua maioria, conteve acessos com formato estrela da cavidade central do fruto. Excetuaram Tainung e STZ 23, que contiveram frutos com formato de pêra; Caliman SG, com formato elongato; e FB, cujo fruto é do tipo clava. Os grupos VI e VII foram constituídos pelos acessos Papaya 45 FR e Mamão roxo, que se diferenciaram por apresentarem colorações do pedúnculo da inflorescência e dos lóbulos da corola, de matizes púrpura e amareloverde com manchas arroxeadas, respectivamente. 
Figura 1. Dendrograma obtido pelo método UPGMA a partir da distância de Mahalanobis entre 46 acessos de mamoeiro caracterizados por descritores quantitativos.

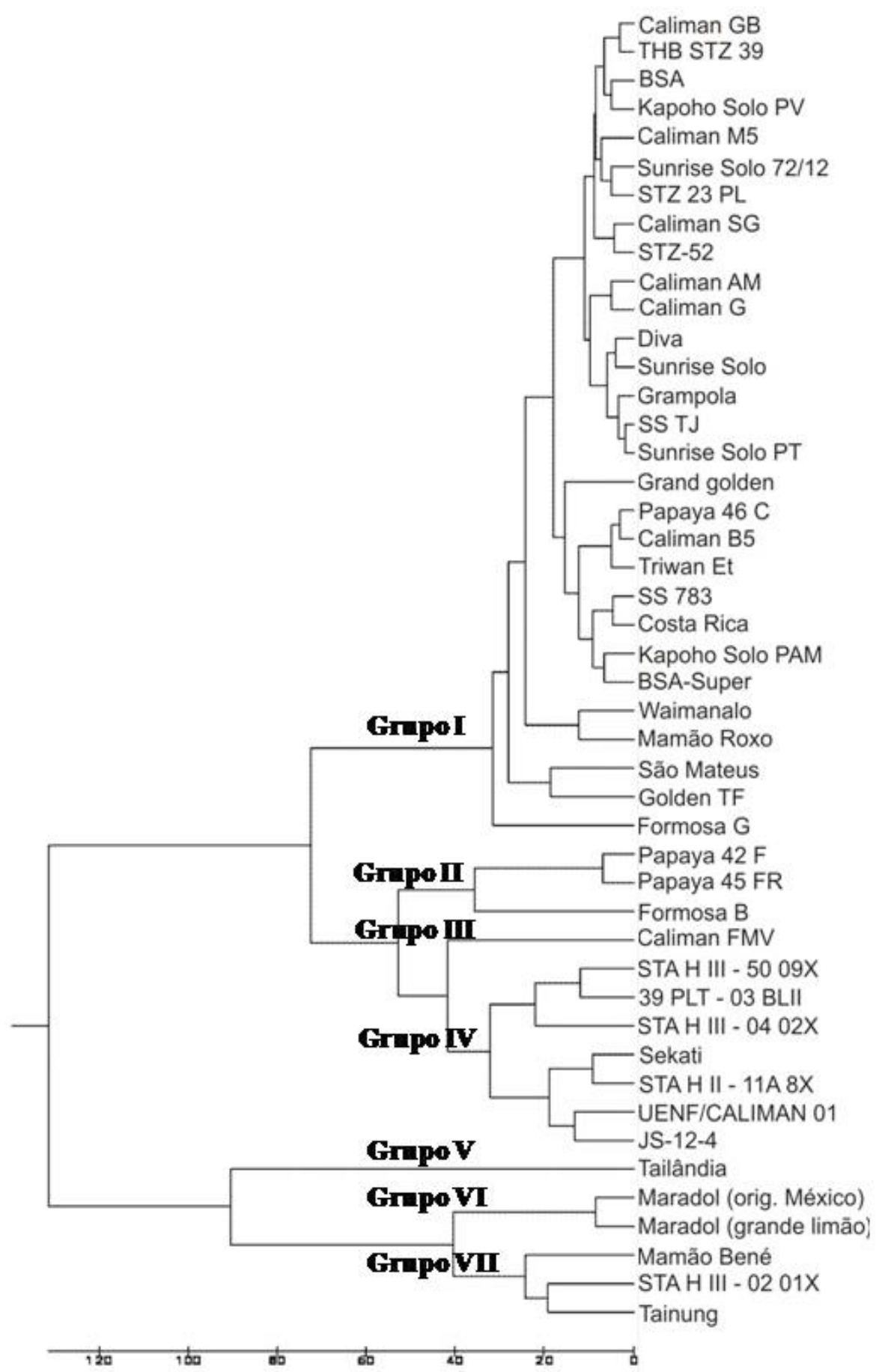

Fonte: Elaboração dos autores. 
Figura 2. Dendrograma obtido pelo método UPGMA a partir do complemento da medida de coincidência simples entre 46 acessos de mamoeiro caracterizados por descritores qualitativos.

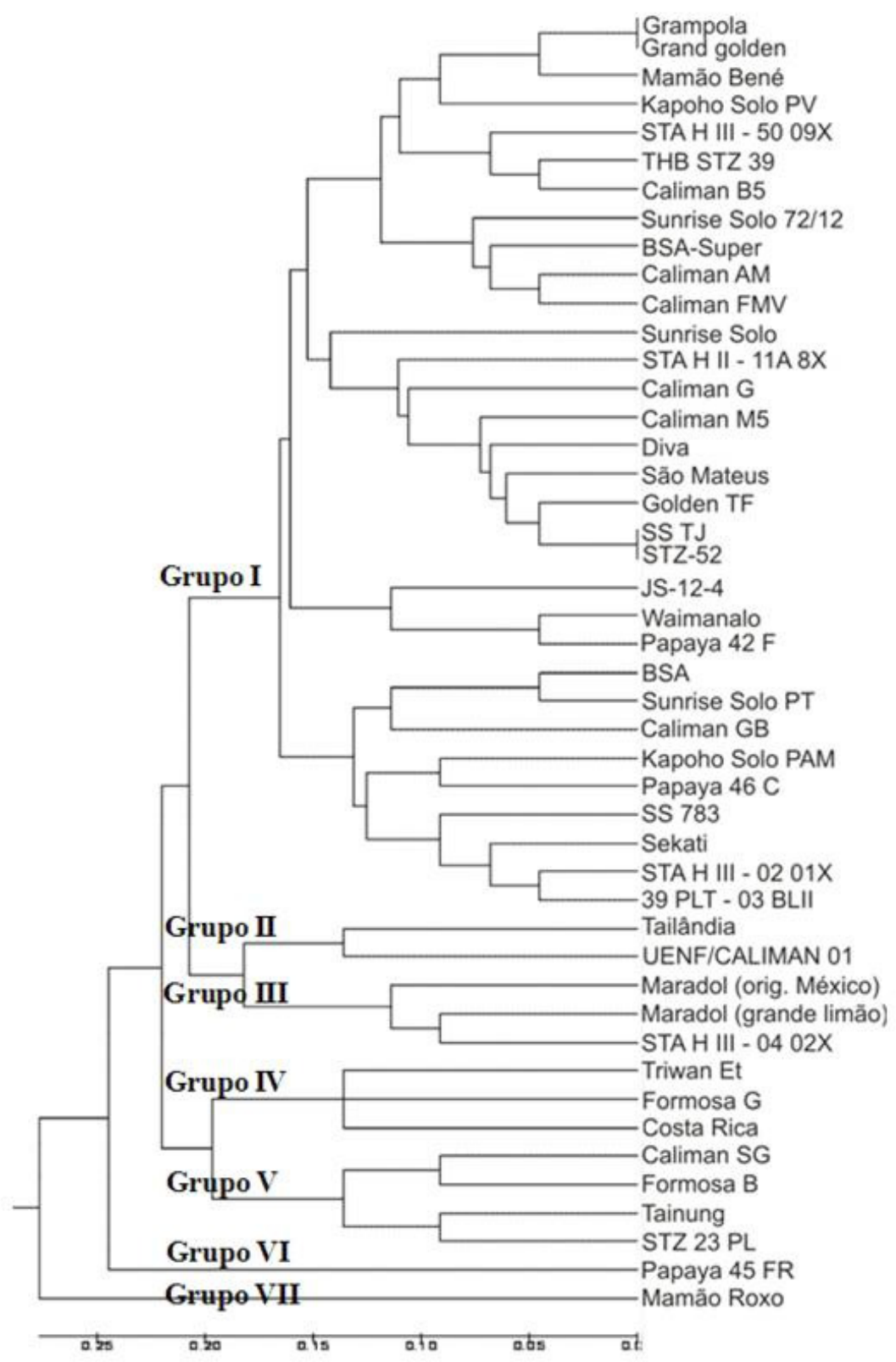

Fonte: Elaboração dos autores.

A estimativa da correlação de Mantel entre as matrizes de distâncias por descritores qualitativos e variáveis quantitativas foi não significativa e de magnitude 0,25. Vieira et al. (2008) avaliando a variabilidade genética entre acessos de mandioca açucarada e não-açucarada, por meio de marcadores moleculares e morfoagronômicos, obtiveram correlações de 0,58 e 0,50 entre marcadores morfoagronômicos quantitativos para com os marcadores morfoagronômicos qualitativos e moleculares, respectivamente, enquanto a correlação entre os marcadores morfoagronômicos qualitativos 
e moleculares foi de 0,83 . Segundo estes autores, a elevada associação entre os marcadores moleculares e os descritores morfoagronômicos qualitativos e a baixa estimativa de correlação entre ambos para com os marcadores morfoagronômicos quantitativos pode ser explicado pelo fato de grande parte da variação detectada pelos marcadores moleculares e características qualitativas avaliadas serem do tipo não adaptativo e, portanto, não sujeita à seleção (natural e artificial), ao contrário das características quantitativas, que estão sujeitos à seleção natural e artificial.

Ao comparar os dendrogramas provenientes das características quantitativas e dos descritores qualitativos, percebe-se que houve apenas semelhança nos grupos de ordem I constituídos pelos dois tipos de variáveis, em decorrência da reunião, em ambos, da maioria dos acessos do grupo Solo. Dos 21 acessos do grupo Solo reunidos no grupo I, oriundos das variáveis quantitativas, somente Caliman SG e Mamão roxo não pertencem ao grupo I formado com base nos descritores qualitativos. Já, em relação aos acessos do tipo Formosa, houve uma dispersão dos indivíduos em praticamente todos os grupos dos dendrogramas constituídos por características quantitativas e para os descritores qualitativos, resultando em alta dessemelhança dos tipos de variáveis na constituição dos grupos. Essa frágil consistência dos grupos formados implica em maior dificuldade para os curadores do banco de germoplasma em relação à identificação de indivíduos parecentes; também, por parte do melhorista haverá maior necessidade de acurácia na identificação de combinações parentais geneticamente distantes, visando à utilização de distintos conjuntos gênicos em cruzamentos para obtenção de híbridos segregantes superiores, ou mesmo, para reconhecer a amplitude da base genética.

Segundo Gonçalves et al. (2008) e com base em rediscussão de Tsivelikas et al. (2009), a análise conjunta dos dados quantitativos e qualitativos pode fornecer uma melhor compreensão da diversidade genética do banco e também verificar se a evidência total está dentro dos limites de confiança dos elementos de cada conjunto de dados. Segundo os mesmos autores, uma caracterização mais completa dos genótipos e dos padrões da diversidade genética contribui na determinação de estratégias futuras para o melhoramento e facilita a introgressão de diversidade no germoplasma estudado.

Houve uma correlação de $0,75(\mathrm{p}<0.001)$ entre a matriz conjunta para com as matrizes provenientes das variáveis quantitativas e descritores qualitativos. O agrupamento com base no algoritmo de Gower proporcionou a formação de oito grupos, considerando a distância média da matriz de agrupamento (Figura 3). Os grupos constituídos pelo algoritmo de Gower foram parcialmente semelhantes aos obtidos pelas variáveis quantitativas e pelos descritores qualitativos, a saber: i) o grupo I, com 23 acessos conteve praticamente todos os acessos de mamoeiro Solo, além do UENF/CALIMAN 01 e Waimanalo, que se alocaram no grupo $\mathrm{V}$, bem como de Mamão roxo, que se fez presente no grupo VI; ii) os acessos Maradol (origem Mexicana) e Maradol (grande limão), compuseram o grupo VIII; e iii) Papaya 45 FR que compôs o grupo VI com base nos descritores qualitativos, também ficou isolado no grupo III para os dados considerados conjuntamente.

No contexto geral, percebe-se uma melhor disjunção dos genótipos, ou seja, uma maior homogeneidade dentro dos grupos e elevada heterogeneidade entre os grupos utilizando-se os dados conjuntamente quando comparados com os dados separadamente. Essa mesma metodologia, também foi utilizada por Rodríguez et al. (2005) para estudar conjuntamente variáveis qualitativas e quantitativas, oriundas de 28 descritores morfoagronômicos em Brassica napus L. Os autores verificaram que a análise conjunta dos dados utilizando a distância de Gower permitiu uma boa estimação da variabilidade. 
Figura 3. Dendrograma obtido pelo método UPGMA a partir da medida de dissimilaridade de Gower entre 46 acessos de mamoeiro caracterizados por descritores quantitativos e qualitativos conjuntamente.

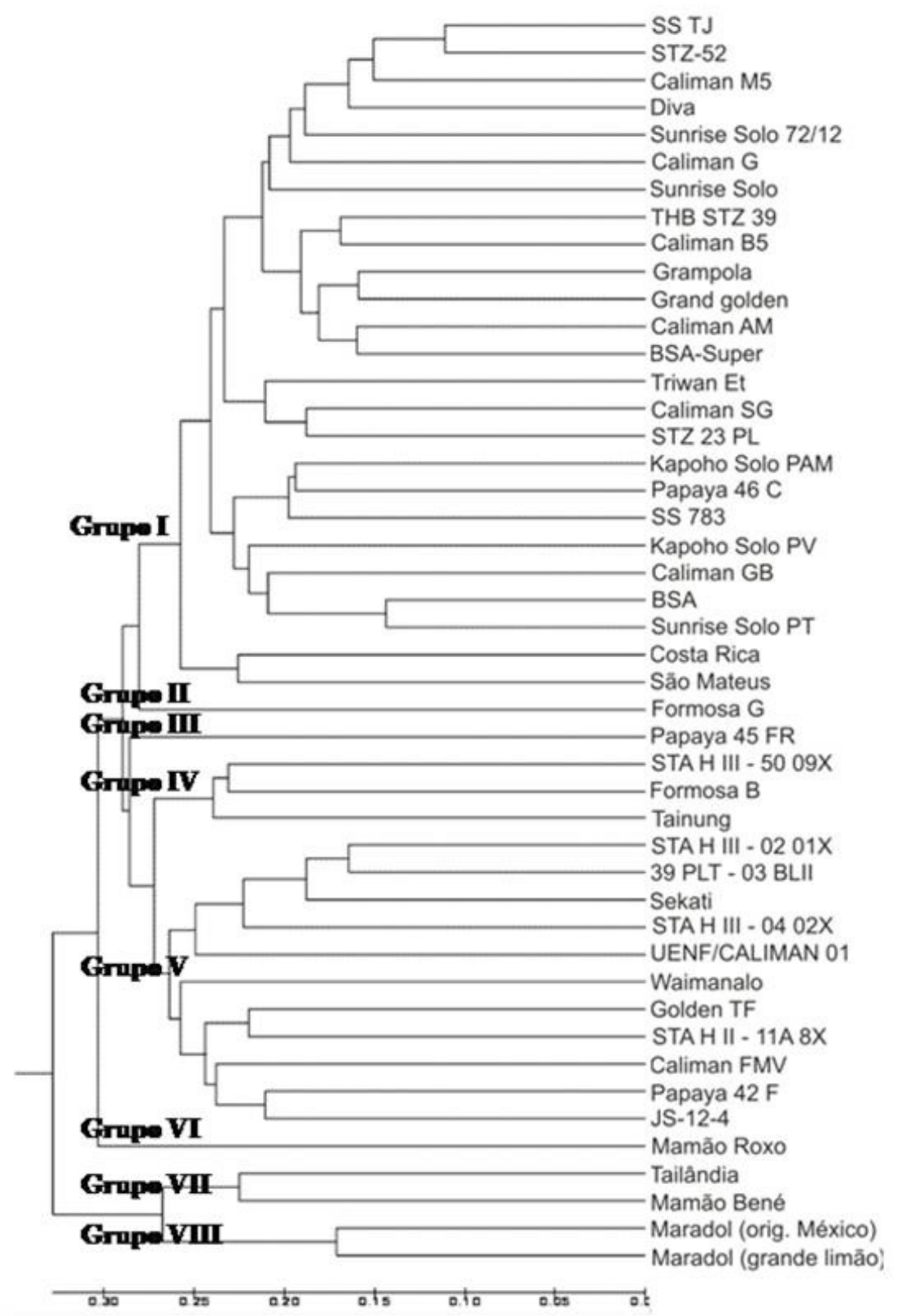

Fonte: Elaboração dos autores. 


\section{Conclusões}

Os acessos de mamão, conservados na coleção de germoplasma da Universidade Estadual do Norte Fluminense Darcy Ribeiro (UENF), apresentaram variabilidade para a maioria dos caracteres morofoagronômicos analisados.

Houve maior variação morfoagronômica nos acessos do grupo Formosa em comparação com grupo Solo.

O algoritmo de Gower foi eficiente na disjunção dos acessos avaliados.

\section{Agradecimentos}

À CALIMAN AGRÍCOLA S/A, pela infraestrutura oferecida;

À FINEP e a UENF, pela oportunidade de condução do trabalho.

\section{Referências}

BERTAN, I.; CARVALHO, F. I. F.; OLIVEIRA, A. C.; BENIN, G.; VIEIRA, E. A.; VALÉRIO, I. P. Morphological pedigree, and molecular distances and their association with hybrid wheat performance. Pesquisa Agropecuária Brasileira, Brasília, v. 44, n. 2, p. 155-163, 2009.

CAVALCANTE, L. F.; CORDEIRO, J. C.; NASCIMENTO, J. A. M.; CAVALCANTE, I. H. L.; DIAS, T. J. Fontes e níveis da salinidade da água na formação de mudas de mamoeiro cv. Sunrise solo. Semina: Ciências Agrárias, Londrina, v. 31, p. 12811290, 2010. Suplemento 1.

CROSSA, J.; FRANCO, J. Statistical method for classifying genotypes. Euphytica, Wageningen, v. 137, n. 1, p. 18-37, 2004.

CRUZ, C. D.; REGAZZI, A. J.; CARNEIRO, P. C. S. Modelos biométricos ao melhoramento genético. Viçosa: UFV, 2004, $390 \mathrm{p}$.

DANTAS, J. L. L.; LIMA, J. F. Seleção e recomendação de variedades de mamoeiro - avaliação de linhagens e híbridos. Revista Brasileira de Fruticultura, Jaboticabal, v. 23, n. 3, p. 617-621, 2001.

EUSTICE, M.; YU, O.; LAI, C. W.; HOU, S.; THIMMAPURAN, J.; LIU, L.; ALAM, M.; MOORE,
P. H.; PRESTING, G. G.; MING, R. Development and application of microsatellite markers for genomic analysis of papaya. Tree Genetics \& Genomes, Davis, v. 4, n. 2, p. 333-341, 2008.

FOOD AND AGRICULTURE ORGANIZATION OF THE UNITED NATIONS - FAO. The agricultural production. 2009. Disponível em: <http://www.faostat. org >. Acesso em: 27 ago. 2009.

FRANCO, J.; CROSSA, J.; TABA, S.; SHANDS, H. A sampling strategy for conserving genetic diversity when forming core subsets. Crop Science, Madison, v. 45, n. 3, p. 1035-1044, 2005.

GEPTS, P. Plant genetic resources conservation and utilization: the accomplishments and future of a societal insurance policy. Crop Science, Madison, v. 46, n. 5, p. 2278-2296, 2006.

GONÇALVES, L. S. A.; RODRIGUES, R.; AMARAL JÚNIOR, A. T.; KARASAWA, M.; SUDRÉ, C. P. Comparison of multivariate statistical algorithms to cluster tomato heirloom accessions. Genetics and Molecular Research, Ribeirão Preto, v. 7, n. 4, p. 12891297, 2008.

. Heirloom tomato gene bank: assessing genetic divergence based on morphological, agronomic and molecular data using a Ward-modified location model. Genetics and Molecular Research, Ribeirão Preto, v. 8, n. 1, p. 364-374, 2009.

GOWER, J. C. A general coefficient of similarity and some of its properties. Biometrics, Arlington, v. 27, n. 3, p. 857-871, 1971.

IBPGR. Descriptors of papaya. FAO: Rome, 1998. 34 p.

IDE, C. D.; PEREIRA, M. G.; VIANA, A. P.; PEREIRA, T. N. S. Use of testers for combining ability and selection of papaya hybrids. Crop Breeding and Applied Biotechnology, Viçosa, v. 9, n. 1, p. 60-66, 2009.

MARIN, S. L. D.; PEREIRA, M. G.; AMARAL JÚNIOR, A. T.; MARTELLETO, L. A.P.; IDE, C. D. Heterosis in papaya hybrids from partial diallel of 'Solo' and 'Formosa' parents. Crop Breeding and Applied Biotechnology, Viçosa, v. 6, n. 1, p. 24-29, 2006 a.

Partial diallel to evaluate the combining ability for economically important traits of papaya. Scientia Agricola, Piracicaba, v. 63, n. 6, p. 540-546, 2006 b.

MARTELLETO, L. A. P.; RIBEIRO, R. L. D.; SURDOMARTELLETO, M.; VASCONCELLOS, M. A. S.; MARIN, S. L. D.; PEREIRA, M. B. Cultivo orgânico do mamoeiro 'Baixinho de Santa Amália' em diferentes ambientes de proteção. Revista Brasileira de Fruticultura, Jaboticabal, v. 30, n. 3, p. 662-666, 2008. 
MIRANDA, G. V.; COIMBRA, R. R.; GODOY, C. L.; SOUZA, L. V.; GUIMARÃES, L. J. M.; MELO, A. V. Potencial de melhoramento e divergência genética de cultivares de milho-pipoca. Pesquisa Agropecuária Brasileira, Brasília, v. 38, n. 6, p. 681-688, 2003.

MOHAMMADI, S. A.; PRASANNA, B. M. Analysis of genetic diversity in crop plants-salient statistical tools and considerations. Crop Science, Madison, v. 43, n. 4, p. 1235-1248, 2003.

MORAIS, P. L. D.; SILVA, G. G.; MENEZES, J. B.; MAIA, F. E. N.; DANTAS, D. J.; SALES JÚNIOR, R. Pós-colheita de mamão híbrido UENF/CALIMAN 01 cultivado no Rio Grande do Norte. Revista Brasileira de Fruticultura, Piracicaba, v. 29, n. 3, p. 666-670, 2007.

MOURA, M. C. C. L.; GONÇALVES, L. S. A.; SUDRÉ, C. P.; RODRIGUES, R.; AMARAL JÚNIOR, A. T.; PEREIRA, T. N. S. Algoritmo de Gower na estimativa da divergência genética em germoplasma de pimenta. Horticultura Brasileira, Brasília, v. 28, n. 2, p. 155-161, 2010.

PINTO, R. M. Avaliação e caracterização de germoplasma de mamão e estabelecimento de descritores mínimos. 1999. Dissertação (Mestrado em Fitotecnia) Universidade Federal da Bahia, Bahia.

RAMOS, N. F.; NASCIMENTO, A. K. Q.; GONÇALVES, M. F. B.; LIMA, J. A. A. Presença dos vírus da mancha anelar e do amarelo letal em frutos de mamoeiro comercializado. Tropical Plant Pathology, Lavras, v. 33, n. 6, p. 449-452, 2008.

ROCHA, M. G.; GONÇALVES, L. S. A.; RODRIGUES, R.; SILVA, P. R. A.; CARMO, M. G. F.; ABBOUD, A. C. S. Uso do algoritmo de Gower na determinação da divergência genética entre acessos de tomateiro do grupo cereja. Acta Scientiarum Agronomy, Maringá, v. 32, n. 3, p. 402-406, 2010.
RODRÍGUEZ, V. M.; CARTEA, M. E.; PADILLA, G.; VELASCO, P.; ORDÁS, A. The nabicol: a horticultural crop in northwestern Spain. Euphytica, Wageningen, v. 142, n. 3, p. 237-246, 2005

SUDRÉ, C. P.; GONÇALVES, L. S. A.; RODRIGUES, R.; AMARAL JÚNIOR, A. T.; RIVA-SOUZA, E. M.; BENTO, C. S. Genetic variability in domesticated Capsicum spp as assessed by morphological and agronomic data in mixed statistical analysis. Genetics and Molecular Research, Ribeirão Preto, v. 9, n. 1, p. 283-294, 2010.

SUZUKI, M. S.; ZAMBOLIM, L.; LIBERATO, J. R. Progresso de doenças fúngicas e correlação com variáveis climáticas em mamoeiro. Summa Phytopathologica, Botucatu, v. 33, n. 2, p. 167-177, 2007.

TSIVELIKAS, A. L.; KOUTITA, O.; ANASTASIADOU, A.; SKARACIS, G. N.; TRAKA-MAVRONA, E.; KOUTSIKA-SOTIRIOU, M. Description and analysis of genetic diversity among squash accessions. Brazilian Archives of Biology and Technology, Botucatu, v. 52, n. 2, p. 271-283, 2009.

VIEIRA, E. A.; CARVALHO, F. I. F.; BERTAN, I.; KOPP, M. M.; ZIMMER, P. D.; BENIN, G.; SILVA, J. A. G.; HARTWING, I.; MALONE, G.; OLIVEIRA, A. C. Association between genetic distances in wheat (Triticum aestivum L.) as estimated by AFLP and morphological markers. Genetics and Molecular Biology, Ribeirão Preto, v. 30, n. 2, p. 392-399, 2007.

VIEIRA, E. A.; FIALHO, J. F.; FALEIRO, F. G.; BELLON, G.; FONSECA, K. G.; CARVALHO, L. J. C. B.; SILVA, M. S.; PAULA-MORAES, S. V.; SANTOS FILHO, M. O. S.; SILVA, K. N. Divergência genética entre acessos açucarados e não açucarados de mandioca. Pesquisa Agropecuária Brasileira, Brasília, v. 43, n. 12, p. 1707-1715, 2008. 